\title{
Keep Your Friends Close: Cell-Cell Contact and Skeletal Myogenesis
}

\author{
Robert S. Krauss, Giselle A. Joseph, and Aviva J. Goel \\ Department of Cell, Developmental, and Regenerative Biology, Graduate School of Biomedical Sciences, \\ Icahn School of Medicine at Mount Sinai, New York, New York 10029 \\ Correspondence: robert.krauss@mssm.edu
}

\begin{abstract}
Development of skeletal muscle is a multistage process that includes lineage commitment of multipotent progenitor cells, differentiation and fusion of myoblasts into multinucleated myofibers, and maturation of myofibers into distinct types. Lineage-specific transcriptional regulation lies at the core of this process, but myogenesis is also regulated by extracellular cues. Some of these cues are initiated by direct cell-cell contact between muscle precursor cells themselves or between muscle precursors and cells of other lineages. Examples of the latter include interaction of migrating neural crest cells with multipotent muscle progenitor cells, muscle interstitial cells with myoblasts, and neurons with myofibers. Among the signaling factors involved are Notch ligands and receptors, cadherins, Ig superfamily members, and Ephrins and Eph receptors. In this article we describe recent progress in this area and highlight open questions raised by the findings.
\end{abstract}

$S_{\text {the vertebrate body and necessary for breath- }}^{\text {keletal muscle is the most abundant tissue in }}$ ing, metabolic homeostasis, and locomotion. Development of skeletal muscle occurs in a sequential, multistage process that includes specification of multipotent progenitors to lineagecommitted myoblasts, differentiation of myoblasts into multinucleated myofibers, and maturation of myofibers by innervation and bundling into functional muscles (Biressi et al. 2007; Comai and Tajbakhsh 2014; Tintignac et al. 2015). Myoblast differentiation is itself a complex process that involves both induction of the muscle-specific transcriptome and fusion of myoblasts into an elongated syncytium. Similarly, maturation is multifaceted. Mature myofibers are classified as "slow" or "fast" types, based on expression of distinct myosin heavy chain (MyHC) isoforms and metabolic capabilities (Schiaffino and Reggiani 2011; Talbot and Maves 2016).

Myogenic specification and differentiation are coordinated by the myogenic basic helixloop-helix (bHLH) transcription factors Myf5, MyoD, myogenin, and MRF4. Uncommitted progenitor cells are specified to become lineage-committed myoblasts through the combined actions of Myf5, MRF4, and MyoD, whereas differentiation of myoblasts is regulated by myogenin, MyoD, and MRF4 (Tapscott 2005; Biressi et al. 2007; Comai and Tajbakhsh 2014). Expression of these factors, particularly MyoD, in many nonmuscle cell types converts such cells to the skeletal muscle program, revealing their

Editors: Carien M. Niessen and Alpha S. Yap

Additional Perspectives on Cell-Cell Junctions available at www.cshperspectives.org

Copyright (C) 2017 Cold Spring Harbor Laboratory Press; all rights reserved; doi: 10.1101/cshperspect.a029298

Cite this article as Cold Spring Harb Perspect Biol 2017;9:a029298 
R.S. Krauss et al.

ability to drive tissue-specific transcription and cell differentiation (Tapscott 2005; Fong and Tapscott 2013). The ability of MyoD to function in this manner occurs in conjunction with nonmuscle-specific factors such as its heterodimeric partners, the E proteins; members of the Mef2 family of transcription factors; transcriptional coactivators; and chromatin remodeling factors (Tapscott 2005; Biressi et al. 2007; Sartorelli and Juan 2011; Fong and Tapscott 2013; Comai and Tajbakhsh 2014). These and additional transcription factors orchestrate development of the skeletal muscle lineage.

Although the importance of lineage-specific transcriptional regulation in skeletal myogenesis has long been appreciated, myogenesis is also regulated by extracellular cues that initiate intracellular signaling (Guasconi and Puri 2009). Some of these extracellular cues are secreted factors, such as fibroblast growth factor (Fgf ), Wnt family ligands, and Sonic hedgehog (Shh). A growing body of evidence indicates that signaling initiated by direct cell-cell contact also provides key regulatory information during development of the skeletal muscle lineage. In adult skeletal muscle, stable cell-cell junctions (exemplified by epithelial, cadherin-based adherens junctions) do not appear to exist between myofibers, which are the unit cells of this tissue. (Cell-cell junctions do exist between myofibers and skeletal muscle stem cells known as satellite cells; this is discussed below.) Nevertheless, cell-cell adhesion, and signaling that derives from cell-cell contact, occurs between various muscle precursor cells and between these cells and nonmuscle cell types during myogenesis. Furthermore, such interactions are important for muscle development. In this review, we discuss the roles and mechanisms whereby cellcell contact regulates skeletal myogenesis.

\section{PROGENITOR CELL COMMITMENT TO THE SKELETAL MUSCLE CELL LINEAGE}

In vertebrates, skeletal muscles of the trunk and limbs develop from somites, transiently existing blocks of columnar epithelial cells that form in an anterior-to-posterior manner from paraxial mesoderm. Somites mature dorsally into the dermomyotome, which has epithelial character and gives rise to skeletal muscle and dermis, and ventrally into the sclerotome, which has mesenchymal character and gives rise to the bones and cartilage of the axial skeleton (Brand-Saberi and Christ 2000). Some dermomyotomal progenitor cells undergo an epithelial-mesenchymal transition (EMT), become committed to the skeletal muscle lineage, and migrate between the dermomyotome and sclerotome to form the myotome, a set of differentiated embryonic muscle cells. Subsequent embryonic, fetal, and postnatal stages of myogenesis involve additional muscle progenitors that originally migrate from the dermomyotome and ultimately establish the trunk and limb musculature (Biressi et al. 2007; Comai and Tajbakhsh 2014).

Signals from the adjacent dorsal neural tube and surface ectoderm play important roles in maturation of the dorsal somite (Munsterberg and Lassar 1995; Stern and Hauschka 1995). These tissues secrete Wntl and Wnt3a, which signal via the "canonical" pathway to stimulate $\beta$-catenin/T-cell factor (TCF)-dependent transcription. These Wnt ligands promote myogenesis of explanted epithelial somites in vitro (Munsterberg et al. 1995; Stern et al. 1995; Tajbakhsh et al. 1998; Borello et al. 2006). Furthermore, an enhancer that regulates Myf5 expression in the dorsal somite harbors TCF binding sites that are critical for Wnt responsiveness and enhancer function (Borello et al. 2006) (N.B.: Myf5 is the first myogenic bHLH factor expressed during development, and its role is solely in lineage determination.) These results argued that canonical Wnt ligands, along with Shh and soluble bone morphogenetic protein (BMP) inhibitors (Munsterberg et al. 1995; Reshef et al. 1998; Borycki et al. 1999), induce muscle lineage specification of dermomyotomal progenitor cells via $\beta$-catenin/TCF-dependent expression of Myf5.

$\beta$-catenin is well known for having two distinct cellular functions: (1) as a transcriptional regulator that associates with the DNA-binding TCF proteins in a Wnt signaling-responsive manner; and (2) as an adaptor protein that binds to the cytoplasmic tail of cadherins and promotes linkage to the cytoskeleton (van 
Amerongen and Nusse 2009; Niessen et al. 2011). Cells of the epithelial dermomyotome express the cell-cell adhesion molecule N-cadherin with an apical localization; its adhesive junction partner, $\beta$-catenin, is localized there as well (Cinnamon et al. 2006). Studies with chick embryos suggest that changes in N-cadherin expression and subcellular localization play important roles in specification of multipotent dermomyotomal cells to the muscle lineage. As these cells divide, $\mathrm{N}$-cadherin is asymmetrically localized in cells that are fated to become skeletal muscle cells of the myotome; conversely, daughter cells that lack N-cadherin take on features of early dermal cells (Cinnamon et al. 2006). Consistent with these observations, electroporation of wild-type or dominant negative mutant forms of $\mathrm{N}$-cadherin into dermomyotomal cells promoted or diminished contribution of such cells to the myotome compartment, respectively (Cinnamon et al. 2006). During EMT of dermomyotomal cells that were fated to become muscle, the apical distribution of $\mathrm{N}$-cadherin and $\beta$-catenin was disrupted, consistent with a transient loss of adhesion during migration and acquisition of the myogenic fate (Cinnamon et al. 2006).

Based on the results described above, the adhesive and transcriptional "pools" of $\beta$-catenin in dermomyotomal muscle progenitor cells might be viewed as distinct; that is, they are involved in either cell-cell adhesion or Wnt signal-dependent activation of Myf5 expression, but not both. However, nuclear $\beta$-catenin signaling from adhesion complexes can occur (McCrea et al. 2015), and recent results from the Marcelle group suggest that this process may be involved in commitment of dermomyotomal progenitor cells to the muscle lineage. These investigators have studied the role of neural crest cells in promoting somitic myogenesis. Neural crest cells migrate from the dorsal neural tube to populate various structures of the embryo. Some of these cells migrate past the dorsomedial aspect of somites, a portion of the dermomyotome known to give rise to myoblasts early in myotome formation. Neural crest cells in close proximity to such dermomyotomal cells express the Notch ligand, Delta1, and cells of the dermomyotome express Notch receptors (Rios et al. 2011). Transient cell-cell contact between migrating, Delta ${ }^{+}$neural crest cells and Notch ${ }^{+}$muscle progenitors in the dermomyotome leads to Notch signaling in the latter. This is, in turn, required for Myf5 induction and adoption of the skeletal muscle cell fate (Rios et al. 2011). This "kiss and run" mode of cellcell contact-dependent signaling strongly suggests that the concurrent timing of neural crest cell migration and myotome formation is mechanistically linked.

Canonical Notch signaling involves cleavage of its intracellular domain (NICD), which translocates to the nucleus and binds RBP-J to stimulate pathway-responsive gene expression (Fortini 2009). In exploring how Notch signaling promotes Myf5 expression in dermomyotomal progenitor cells, it was found that NICD inhibited GSK3 $\beta$ activity independently of NICD's transcriptional role in the nucleus (Sieiro et al. 2016). This, in turn, led to stabilization of Snail, which promoted EMT of these cells. Unexpectedly, NICD also drove TCF-dependent reporter activity and Myf5 expression, again independently of its canonical transcriptional role. Notch-stimulated, TCF-dependent reporter activity and Myf5 expression were independent of Wnt signaling and appeared to result from liberation of a membrane source of $\beta$-catenin (Sieiro et al. 2016). As described above, EMT of dermomyotomal cells was accompanied by loss of $\mathrm{N}$-cadherin and $\beta$-catenin from an apical junction location. It may be that the reduction in cell-cell adhesion that allows muscle progenitor cells to migrate out of the dermomyotome (and which is promoted by the EMT program) allows $\beta$-catenin to relocalize from the plasma membrane to the nucleus and specify the myogenic cell fate via TCF-dependent induction of Myf5 (Fig. 1). The mechanism by which $\beta$-catenin is relocalized is not clear, but expression of a phosphorylation-deficient $\beta$-catenin mutant that is poorly mobilized from junctional complexes was ineffective in $M y f 5$ induction. Therefore, $\beta$-catenin may be phosphorylated during EMT to trigger alteration of its subcellular localization. Taken together, these results uncovered a novel mecha- 
R.S. Krauss et al.
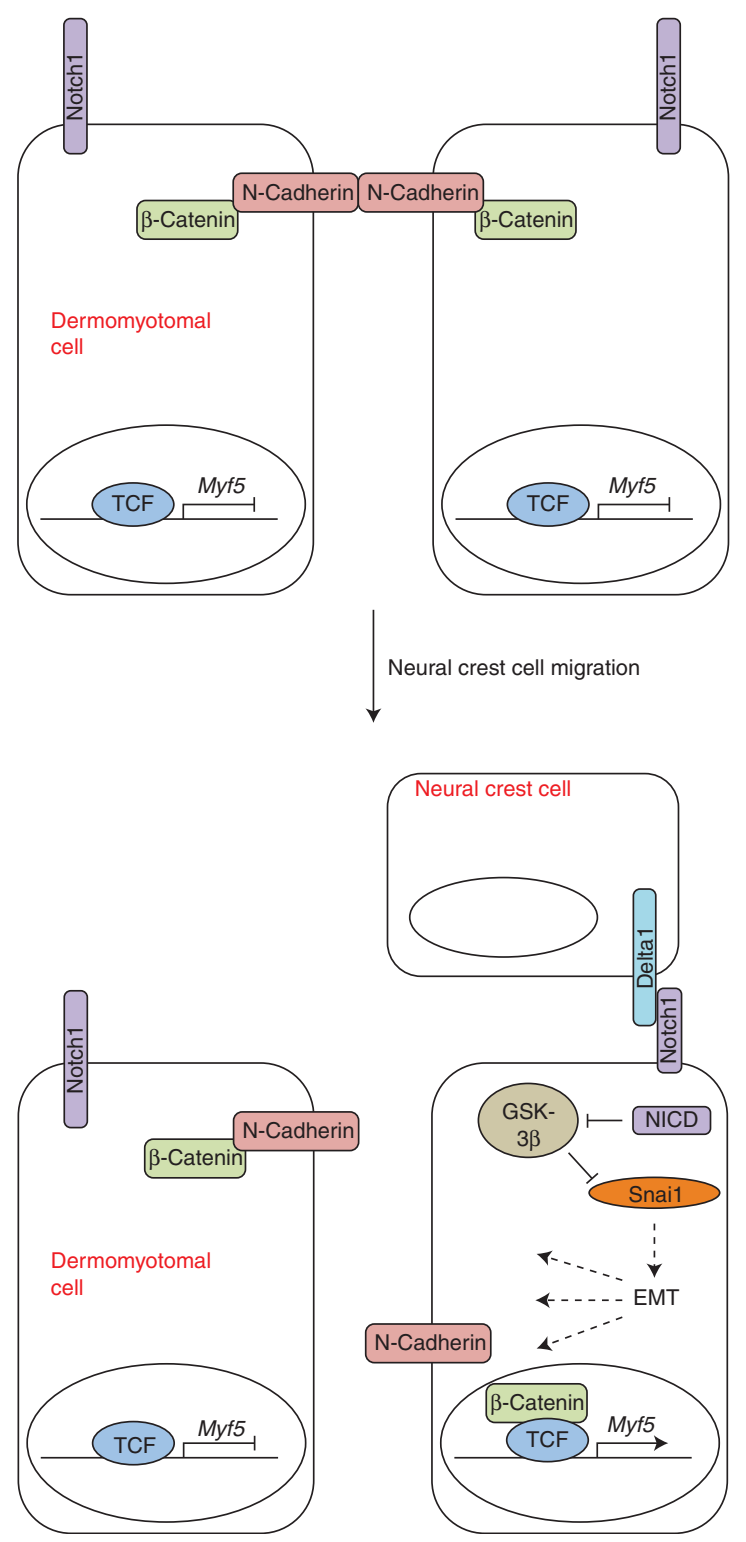

Figure 1. Delta/Notch signaling from migrating neural crest cells to dermomyotomal muscle progenitor cells stimulates translocation of $\beta$-catenin from adhesive junctions to the nucleus to promote $M y f 5$ expression and myogenic commitment. Before engagement with a neural crest cell (top), dermomyotomal cells express $\mathrm{N}$ cadherin and $\beta$-catenin in an apical location. The $M y f 5$ gene is not expressed and the cells are multipotent. When neural crest cells migrate across the surface of the dorsal somite, Delta1 on their surface binds to Notch1 on the surface of dermomyotomal cells (bottom). This leads to cleavage of the Notch intracellular domain (NICD), which acts in the cytoplasm to inhibit GSK-3 $\beta$, in turn stabilizing Snail. Snail induces an epithelial-mesenchymal transition (EMT). The dashed line between Snail and EMT indicates that this is a complex event; the multiple dashed lines emanating from EMT indicate that EMT induces multiple profound changes to the cell. Among these, $\mathrm{N}$-cadherin no longer localizes to an apical site and $\beta$-catenin translocates from an adhesive junction to the nucleus where it associates with TCF to induce expression of Myf5. Expression of Myf5 commits progenitor cells to the skeletal muscle lineage. Alterations in $\mathrm{N}$-cadherin localization are also associated with asymmetric cell divisions (not shown, but see text for further details). 
nism whereby contact between migrating neural crest cells and dermomyotomal progenitor cells triggers a nontranscriptional Notch signaling function. This noncanonical Notch signal promotes a change in cell adhesion and redirection of $\beta$-catenin's function from the membrane to the nucleus, thereby stimulating myogenic cell fate acquisition (Sieiro et al. 2016).

These findings raise numerous questions. If Notch-dependent $\beta$-catenin/TCF activity is key to myogenic specification, what is the role of canonical Wnt signaling-which can be observed and is distinguishable from the Notch/ $\beta$-catenin activity - in this process? What kinases maybe involved in $\beta$-catenin phosphorylation and how is their activity regulated? Is $\mathrm{N}$-cadherin the $\beta$-catenin partner that releases the "pool" of $\beta$-catenin in this process or are other cadherins involved? We note that $\mathrm{P}$-cadherin, and perhaps additional cadherins, is also expressed in the epithelial dermomyotome (Thuault et al. 2013). How do these new findings relate to the earlier results on $\mathrm{N}$-cadherin in myogenic specification via asymmetric cell divisions (Cinnamon et al. 2006)? Canonical Notch signaling plays roles later in myogenesis, including inhibition of myoblast differentiation such that appropriate numbers of myoblasts are produced (SchusterGossler et al. 2007; Vasyutina et al. 2007); how, if at all, are these two Notch functions related? Finally, these findings are compelling, but have been performed only with electroporated chick embryos. It will be interesting and important to address the pathway with conditional mutants in mouse embryos also.

\section{MYOBLAST DIFFERENTIATION AND FUSION}

Differentiation of skeletal myoblasts into myofibers is a multistep process involving withdrawal from the cell cycle, adoption of a muscle-specific transcriptional program, cell elongation, and cell-cell fusion (Biressi et al. 2007; Comai and Tajbakhsh 2014). Cell-cell contact is, of course, a prerequisite for fusion of myoblasts with each other or with nascent myofibers, but the myoblast differentiation program as a whole is regulated by direct cell-cell contact. It is high- ly likely that changes in gene expression and cell morphology are coordinated during differentiation to produce this very specialized cell type. The mechanisms by which this coordination occurs are not fully clear, but cell-cell contact between myoblasts is likely to play a role.

Myogenic differentiation is amenable to analysis in vitro, as both primary mouse myoblasts and myoblast cell lines are easily obtained and studied. Myoblasts are generally allowed to proliferate in mitogen-rich medium until near confluence, at which point they are switched to mitogen-poor medium to stimulate differentiation. Although growth factor deprivation is a primary differentiation signal in these cultures, high cell density itself is strongly promyogenic. It was subsequently showed that cell-cell contact and adhesion regulates promyogenic signal transduction pathways. Multiple mechanisms underlie this effect, and we have reviewed the field previously (Krauss et al. 2005; Krauss 2010).

A central factor in cell contact-dependent signaling in myoblasts is the multifunctional cell-surface coreceptor, Cdon (also called Cdo). Cdon has multiple immunoglobulin (Ig) and FNIII repeats in its extracellular region, a single transmembrane region, and a long cytoplasmic tail that does not resemble other proteins and lacks known catalytic activity (Kang et al. 1997, 1998). Cdon binds in cis to several different adhesion molecules and signaling receptors, and it can serve in ligand binding or signal propagation, depending on the receptor complex in question. One major binding partner for Cdon in skeletal myoblasts is $\mathrm{N}$-cadherin (Kang et al. 2003; Lu and Krauss 2010). Trans-ligation of $\mathrm{N}$-cadherin on adjacent myoblasts stimulates assembly of signaling complexes on the Cdon intracellular region (Fig. 2). These include direct association with (1) Bnip-2, which binds and brings to the complex the small GTPase, Cdc42 (Kang et al. 2008); and (2) JLP, a scaffold protein for the $\mathrm{p} 38 \alpha / \beta$ mitogen-associated protein (MAP) kinase pathway (Takaesu et al. 2006). Formation of such complexes stimulates Cdc42-dependent activation of $\mathrm{p} 38 \alpha / \beta$ (hereafter, p38) via a cascade of kinases that includes Pak1/2, Tak1 and/or Ask1, and MKK3/6 (Wu et al. 2000; Takaesu et al. 2006; Tran et al. 2012; 
R.S. Krauss et al.

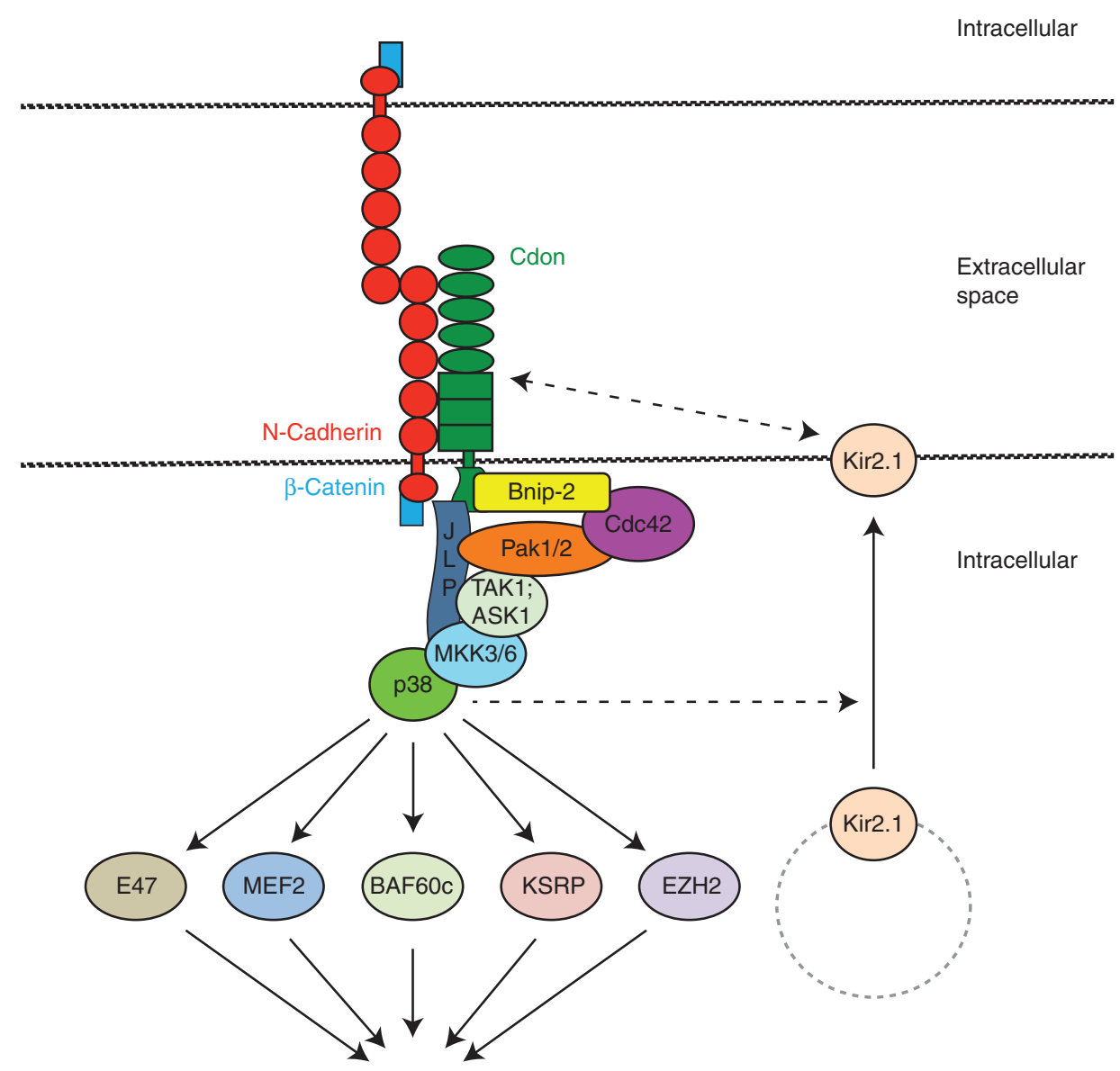

MyoD-dependent, muscle-specific gene expression

Figure 2. N-cadherin ligation between myoblasts stimulates Cdon-dependent activation of p38, which promotes myogenic differentiation. N-cadherin ligation occurs on contact and adhesion of myoblasts and this, in turn, leads to assembly of signaling complexes on the intracellular region of Cdon. The scaffold protein Bnip-2 associates with both Cdon and Cdc42. Activated Cdc42 signals via Pak1/2 kinases to stimulate a p38 MAP kinase cascade bound to the Cdon-associated scaffold protein JLP. Activated p 38 phosphorylates substrates that promote MyoD-dependent, muscle-specific gene expression to drive differentiation; among these substrates are E47, MEF2, BAF60c, KSRP, and EZH2. p38 activity also promotes cell-surface localization of the potassium channel, Kir2.1, which associates with Cdon. The dashed lines indicate that the p38 substrate involved in trafficking of Kir2.1 is not identified, and it is not clear whether the association between Cdon and Kir2.1 is a direct one. The dashed circle indicates that Kir2.1 is likely in a vesicular location before p38 activation, but the specific trafficking events that lead to cell-surface localization are not known. See text for further details. MAP, Mitogen-associated protein.

Joseph and Krauss, in prep). Activated p38, in turn, promotes myogenic differentiation through phosphorylation of proteins that stimulate the muscle-specific transcriptional activity of MyoD. Among these promyogenic p38 substrates are the MyoD dimeric partner, E47;
MEF2 proteins; the SWI-SNF chromatin remodeling complex subunit BAF60c; the RNA decay-promoting factor KSRP; and the polycomb repressive complex 2 catalytic subunit, EZH2 (Fig. 2) (Wu et al. 2000; Simone et al. 2004; Briata et al. 2005; de Angelis et al. 2005; 
Lluis et al. 2005; Rampalli et al. 2007; Serra et al. 2007; Palacios et al. 2010).

Kang and colleagues recently showed that, in addition to its transcriptional regulatory function, Cdon-dependent p38 activation also promoted cell-surface expression of the inwardly rectifying potassium channel, Kir2.1 (Leem et al. 2016). Furthermore, Cdon and Kir2.1 formed complexes with each other at the cell surface. Importantly, plasma membrane hyperpolarization mediated by Kir2.1 promoted myoblast differentiation (Fischer-Lougheed et al. 2001; Konig et al. 2004). Cdon ${ }^{-/-}$myoblasts displayed both defective differentiation and defective Kir2.1 activity, both of which could be rescued by expression of a constitutively active form of the p38 upstream activating kinase, MKK6 (Leem et al. 2016). Cdon expression is itself up-regulated by MyoD (Cole et al. 2004). Cell-cell adhesion between myoblasts, therefore, helps stimulate a complex feedback network of signaling and transcriptional regulation that reinforces both cell surface and nuclear drivers of myoblast differentiation (Fig. 2).

Cdon has multiple additional roles that influence skeletal myogenesis. Cdon interacts in cis with the netrin receptor, neogenin (Kang et al. 2004). Like Cdon, neogenin is an Ig and FNIII repeat-containing receptor. Myoblasts produce both netrin-3 ligand and neogenin, suggesting that they function in an autocrine manner (Kang et al. 2004). Although netrins are secreted molecules, in myoblast cultures they are associated with cell membranes and/ or the extracellular matrix, indicating that they signal via short range in these cells, likely contributing to the promyogenic effects of cell-cell contact. Stimulation of primary or $\mathrm{C} 2 \mathrm{C} 12$ myoblasts with netrin led to activation of focal adhesion kinase (FAK) and the extracellular signal-regulated kinase (ERK) MAP kinase (Kang et al. 2004; Bae et al. 2009). ERK, in turn, phosphorylated the calcium sensor Stim1, which promoted activation of the calcium-sensitive, promyogenic transcription factor, NFATc3 (Lee et al. 2012). These netrin-initiated signaling events occurred in a manner that is dependent on both neogenin and Cdon (Kang et al. 2004; Bae et al. 2009). Cdon binds to neogenin, but not to soluble netrin, implying its role is as a coreceptor (Kang et al. 2004), but Cdon's mechanistic function in netrin signaling is less clear here than with cadherin-based signaling. Cdon also serves to regulate the Hedgehog and Wnt pathways (Zhang et al. 2006; Allen et al. 2011; Jeong et al. 2014). However, these are less likely to be cell-cell contact-dependent events, and Cdon's specific role in the ability of these pathways to influence muscle development is not clear. Mice lacking Cdon displayed delayed skeletal muscle development, and primary myoblasts from such mice differentiated defectively in vitro (Cole et al. 2004). The phenotype associated with loss of Cdon may arise from a combination of suboptimal signaling via several of the pathways it regulates.

Myoblast fusion is fundamental to production of myofibers and obviously requires cellcell contact and adhesion. Led by genetic screens in Drosophila and followed by studies in zebrafish and mice, great progress has been made in understanding mechanisms of myoblast fusion. A recent model proposes that three steps underlie myoblast fusion: (1) cell recognition and adhesion, (2) enhancement of cell proximity via F-actin-propelled membrane protrusions by one fusion partner cell and myosin II-dependent cortical tension in the other, and (3) destabilization of the two apposed plasma membrane lipid bilayers and formation of a fusion pore (Kim et al. 2015). Many intracellular components that mediate steps 2 and 3 have been identified in Drosophila and, where tested, appear to be evolutionarily conserved in zebrafish and mice, and cultured cells. In contrast, a clear picture of the factors that mediate cell recognition and adhesion in these different models has not yet emerged. Comprehensive reviews have recently been published on myoblast fusion (Abmayr and Pavlath 2012; Hindi et al. 2013; Kim et al. 2015), and for the purposes of this review, we will focus on open questions pertaining to the cell-cell adhesion molecules involved in this process.

In the Drosophila embryo, fusion takes place between two types of myoblasts: muscle founder cells and fusion competent myoblasts. The former express the related adhesion receptors 
R.S. Krauss et al.

Dumbfounded and Roughest, whereas the latter express the related counter-receptors, Sticksand-stones, and Hibris. All of these are Ig superfamily receptors (Kim et al. 2015). Engagement of these cell adhesion molecules triggers signaling events, which ultimately promote steps 2 and 3 above. The cell-cell contact points at which adhesion molecules and actin-rich protrusions are localized are complex cell-cell junctions and have been likened to synapses (Sens et al. 2010; Duan et al. 2012; Kim et al. 2015). Many intracellular signaling proteins and actin regulatory factors that are required for myoblast fusion in Drosophila are also required for this process in vertebrates (Krauss 2007; Moore et al. 2007; Srinivas et al. 2007; Laurin et al. 2008; Vasyutina et al. 2009; Gruenbaum-Cohen et al. 2012). However, the cell adhesion molecules that are critical for this process in zebrafish and mice may be different from those in Drosophila, and all the critical factors are probably not yet in sight. In zebrafish, a Dumbfounded ortholog (Kirrel31) and a Sticks-and-Stones ortholog (Nephrin) have been assessed for roles in myoblast fusion via morpholino-mediated knockdown. Kirrel31 morphants had a strong fusion defect, suggesting a potentially conserved function, but they also had myofiber attachment defects (Srinivas et al. 2007). Nephrin morphants had shorter, disorganized myofibers but did not display overt loss of myoblast fusion (Sohn et al. 2009). Morpholino-dependent knockdown was, however, inefficient and it may be that a fusion defect would require a greater level of depletion. In contrast, JAM-B and -C, two different Ig superfamily counter-receptors, were essential for myoblast fusion in zebrafish (Powell and Wright 2011). Studies with mice carrying individual mutations in the members of the Kirrel, Nephrin, and JAM families have not been studied specifically for muscle development or myoblast fusion, but most mutants survive long enough that it is not possible for a complete block to myoblast fusion to have occurred in these animals (Donoviel et al. 2001; Putaala et al. 2001; Gliki et al. 2004; Sakaguchi et al. 2006; Prince et al. 2013; Yesildag et al. 2015).

Cadherins have been suggested to play a role as adhesion molecules in myoblast fusion, but there is little genetic evidence to support a critical role of any single cadherin in this process (Charlton et al. 1997; Radice et al. 1997; Hollnagel et al. 2002). One possibility is that the multiple cadherins that are expressed in myoblasts may have overlapping or compensatory functions (Charlton et al. 1997; Radice et al. 1997; Hollnagel et al. 2002; Marthiens et al. 2002). Consistent with this notion is that forced expression of the intracellular region of E-cadherin in C2C12 myoblasts blocked both fusion into myotubes and cell-surface localization of endogenous $\mathrm{N}$ - and $\mathrm{M}$-cadherin (note E-cadherin is not expressed endogenously in these cells, but its intracellular region is similar to that of the other cadherins) (Ozawa 2015). We have recently constructed mice that lack $\mathrm{N}$ - and $\mathrm{M}$-cadherin in the muscle lineage. Although myoblast fusion was not obviously perturbed in these animals, primary myoblasts isolated from them had a specific fusion defect in vitro (AJ Goel and RS Krauss, in prep). This suggests that multiple cadherins may indeed display redundant functions in myoblast fusion, but there may be additional redundancy or requirements in vivo than in vitro.

It is important to note that although Kirrel, Nephrin, Jam, and cadherin family proteins are sufficient to promote cell-cell adhesion, they are not sufficient to drive cell-cell fusion (Martìn-Padura et al. 1998; Galletta et al. 2004; Shilagardi et al. 2013). Furthermore, their expression is not restricted to the skeletal muscle lineage or even to other fusogenic cell types. The identity of a true fusogen in myoblast fusion is, therefore, of very high interest. One possibility here is the recently discovered myomaker, a cell-surface protein with seven membrane-spanning regions (Millay et al. 2013, 2016). Myomaker (also called TMEM8c) is essential for myoblast fusion in both mice and zebrafish (Millay et al. 2013, 2014; Landemaine et al. 2014). It is expressed exclusively in the skeletal muscle lineage and at the times during muscle development and regeneration when fusion is occurring. Significantly, ectopic expression of myomaker in fibroblasts allows them to fuse with myoblasts, an activity not seen previously with any other protein (Millay et al. 2013, 
2016; Landemaine et al. 2014). Whether myomaker is the long sought direct fusogen, or somehow regulates the process in another fundamental way, is not yet clear. However, understanding its mechanism of action, how it might interact with adhesion molecules, and what cellsurface junctional complexes it is a component of are important questions.

Finally, a recent finding has suggested that cell-cell contact and signaling between myoblasts and a nonmyogenic, muscle interstitial cell stimulates neonatal muscle growth in mice by promoting myoblast migration to fusion sites on myofibers ( $\mathrm{Gu}$ et al. 2016). Myofiber formation is thought to be largely complete by birth, but fibers continue to grow during the early postnatal period via fusion of myoblasts at the tips of fibers. Specific, muscle-resident cells that expressed the surface marker NG2 contacted myoblasts to promote their migration to these sites. $\mathrm{NG}^{+}$cells also had high NF-кB activity, which directly regulated expression of ephrin-A5. Signaling by ephrins and their Eph receptors is a widely used mechanism of directed cell motility and migration (Lisabeth et al. 2013). Genetic removal of the p65 subunit of NF- $\kappa$ B or ephrin-A5 from $\mathrm{NG}^{+}$cells showed that these factors were important for the ability of $\mathrm{NG}^{+}$cells to promote myoblast motility in vitro and for proper myoblast localization and fusion in postnatal myofiber growth (Gu et al. 2016). As seen with neural crest cells and somitic muscle progenitors, these intriguing results provide another example of how cell contact-mediated signaling between nonmuscle cell types and muscle precursors regulates specific events in muscle development.

\section{MUSCLE FIBER-TYPE PATTERNING}

Skeletal myofibers are classified into different types by a variety of criteria, including expression of specific isoforms of $\mathrm{MyHC}$, use of glycolytic versus oxidative metabolism, and speed of contraction (i.e., twitch) and fatigue (Schiaffino and Reggiani 2011; Talbot and Maves 2016). A broad classification scheme separates slow-twitch fibers, called Type 1, from fasttwitch fibers, which encompass Types 2A, $2 \mathrm{X}$, and 2B. Slow-twitch and Type 2A fibers use oxidative metabolism. As their name implies, slow-twitch fibers are the slowest contracting and fatiguing of all the myofiber types, with $2 \mathrm{~A}$ fibers being the slowest contracting and fatiguing of the fast-twitch fibers. Type $2 \mathrm{X}$ and $2 \mathrm{~B}$ fibers use glycolytic metabolism, and they contract and fatigue faster than do $2 \mathrm{~A}$ fibers (or, naturally, than slow-twitch fibers).

Fiber type identity begins to be specified during embryonic development. However, late in prenatal development and continuing into the postnatal period, interactions between myofibers and their innervating motor neurons play a key role in stable fiber-type specification. Newly formed myofibers can contact axons from many different motor neurons, but over time all neuromuscular synapses but one, per fiber, are lost. Mature motor neurons innervate many individual fibers, and together these are called motor units. Fiber type identity, including expression of specific isoforms of $\mathrm{MyHC}$, is plastic until myofibers are innervated by a single motor neuron and organized into a motor unit (Sanes and Lichtman 1999). Motor neurons themselves are also categorized into slow versus fast-resistant versus fast-fatigable, based on, among other properties, their firing rate. Within a motor unit, the neuronal firing rate helps specify fiber type. These observations raise the critical question of how motor neurons of the appropriate type interact stably with fibers that already possess some degree of fiber-type identity. Recent work by Cornelison and colleagues implicates ephrins and their cognate Eph receptors in this process (Stark et al. 2015).

Of eight ephrins screened for expression in adult mouse muscle, only ephrin-A3 was expressed in a nonuniform pattern (Stark et al. 2015). Costaining for the various types of $\mathrm{MyHC}$ revealed that ephrin-A3 was expressed exclusively on Type 1 (slow) fibers and that all such fibers were positive for ephrin-A3 (Stark et al. 2015). Ephrin-A3 expression on such fibers initiated after expression of MyHC-I (the isoform expressed by slow fibers), indicating that it is a part of the program that characterizes the early, cell-autonomous slow fiber program. To assess a role for ephrin-A3 in fiber-type pat- 
R.S. Krauss et al.

terning, a series of genetic experiments were performed. The number of $\mathrm{MyHC}^{+}{ }^{+}$fibers was not different between control and ephrinA3-null mice through the first two weeks of postnatal life. However, between P14 and adulthood, the mutant mice underwent a striking diminution in numbers of slow fibers in most hind limb muscles, without a change in overall fiber number (Stark et al. 2015). Taken together, these results suggested that ephrin-A3 is dispensable for early specification of the slow fiber type, but is required for the process whereby fiber type identity is solidified and maintained by motor neuron engagement. To further test this notion, ephrin-A3 was ectopically expressed via in vivo plasmid electroporation of the anterior region of the adult Tibialis anterior muscle, which normally contains no slow fibers. This was followed by a sciatic nerve crush denervation protocol, which stimulates reinnervation by endogenous repair processes. Electroporation of a control plasmid was without effect, irrespective of whether denervation had occurred, and expression of ephrin-A3 in myofibers was without effect in the absence of denervation; however, ephrin-A3 expression followed by denervation resulted in production of abundant slow fibers in the electroporated area. These data are consistent with the conclusion that ephrin-A3 plays a role in motor neurondependent fiber-type specification and patterning, both during normal muscle maturation and reinnervation after injury.

As Ephrins bind their cognate Eph receptors during cell-cell interactions to provide contactbased repulsion signals (Lisabeth et al. 2013), these investigators searched for Eph receptors with a reciprocal expression pattern to ephrinA3. EphA8 was found to be expressed at the neuromuscular junctions of fast, but not slow, fibers (Stark et al. 2015). Interestingly, the cell type on which synaptic EphA8 is expressed is a nonmyelinating glial cell present at neuromuscular junctions called terminal Schwann cells. Taken together, these results lead to the following model: After early specification during embryonic development, $\mathrm{MyHC}-\mathrm{I}^{+}$slow fibers express ephrin-A3. Many motor axons of both slow and fast subtypes can make contact with these fibers (with fast axons outnumbering slow ones), leading to polyinnervation. During the 2- to 4-week postnatal period, $\mathrm{MyHC}-\mathrm{I}^{+} /$ ephrin-A3 ${ }^{+}$fibers become stably monoinnervated only by neurons whose Schwann cells lack EphA8; in contrast, neuromuscular junctions that harbor EphA8 ${ }^{+}$Schwann cells are found only on fast fibers, which lack ephrinA3 (Stark et al. 2015). It is logical to propose, therefore, that cell contact-based repulsion between $\mathrm{MyHC}-\mathrm{I}^{+} / \mathrm{ephrin}^{\mathrm{A}} 3^{+}$fibers and EphA $8^{+}$ presynaptic termini promotes stable monoinnervation of slow fibers by only EphA $8^{-}$synapses. In contrast, ephrin-A3 ${ }^{-}$(fast) fibers can be monoinnervated by EphA $8^{+}$synapses. This cell-cell contact-based mechanism can explain at least some of the final reciprocal patterns of myofiber types and their associated motor neurons, and the overall pattern of slow versus fast fiber types.

\section{SATELLITE CELL-MYOFIBER INTERACTIONS}

Adherens junction-like structures are not known to exist between skeletal myofibers. (It is worth noting that "cardiomyocytes" do have such structures (Vite and Radice 2014.) However, adult myofibers have stable cell-cell junctions in two notable cases. One is the neuromuscular junction. This is a complex synapse essential for nervous control of muscle contraction. Development and maintenance of the neuromuscular junction is beyond the scope of this review, which is focused on myogenesis, and readers are directed to a review on this topic (Tintignac et al. 2015). The second is the junction that exists between myofibers and their associated satellite cells. Satellite cells are adult skeletal muscle stem cells located between the myofiber and its surrounding basal lamina, and they are the source of skeletal muscle's remarkable regenerative properties (Brack and Rando 2012; Doles and Olwin 2015; Dumont et al. 2015). Unlike tissues such as the epidermis or hematopoietic system, myofibers are not replenished homeostatically, and as such, satellite cells do not play a major role in maintenance of adult skeletal muscle (Fry et al. 2015; Keefe et al. 2015). Therefore, satellite cells exist in a largely 
quiescent state in adult mice. However, on muscle injury they are activated to proliferate and produce the myoblasts that will ultimately differentiate to form new myofibers; they also selfrenew to replenish the muscle stem cell compartment (Brack and Rando 2012; Doles and Olwin 2015; Dumont et al. 2015).

Within their niche, satellite cells display polarized adhesive interactions (Fig. 3). On their basal side, they express integrins (e.g., integrin $\alpha 7 \beta 1$ ) that bind laminins present in the basal lamina that enwraps each individual myofiber. On their apical side, satellite cells are directly apposed to the plasma membrane of their associated myofiber. M-cadherin, a muscle-specific classical cadherin, is localized exclusively at the site of contact between the satellite cell and the fiber. Quiescence is the hallmark property of satellite cells, and it is widely believed that the satellite cell niche plays a role in its maintenance. This is important as in instances in which quiescence is inappropriately broken, satellite cell number and/or function is diminished (Fukada et al. 2011; Bjornson et al. 2012; Chakkalakal et al. 2012; Cheung et al. 2012; Mourikis et al. 2012; Gopinath et al. 2014; Dumont et al. 2015). In 1990, Bischoff (1990) reported that myofibers themselves are an important component of the quiescence-inducing niche. These results indicated that direct cell-cell interactions between myofibers and satellite cells were likely to regulate this key property of the latter.

The molecular mechanisms that underlie the ability of myofibers to promote satellite cell quiescence are poorly understood. However, Notch signaling is critical to the maintenance of satellite cell quiescence (Bjornson et al. 2012; Mourikis et al. 2012). A transgenic Notch reporter construct showed activity in quiescent satellite cells in vivo, and freshly isolated satellite cells expressed high levels of direct Notch pathway target genes such as Hes1, Heyl, and HeyL. Expression of these genes was sharply diminished when satellite cells were activated in response to injury in vivo or cultured under activating conditions in vitro. RBP-J is a DNA-

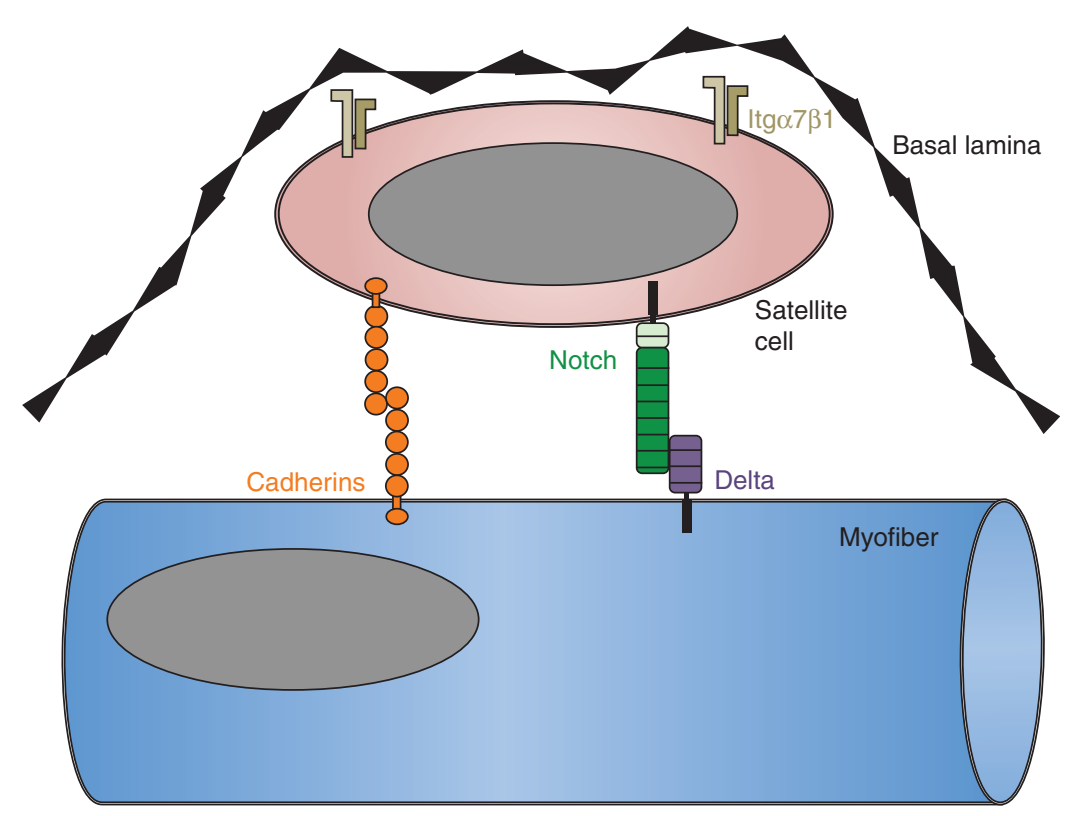

Figure 3. Quiescent satellite cells are polarized and form cell-cell junctions with myofibers. Satellite cells reside between myofibers and their surrounding basal lamina. Cadherins and Notch receptors are localized to the apical membrane of satellite cells and bind to cadherins and Notch ligands (e.g., Delta) on the myofiber membrane. Integrin $\alpha 7 \beta 1$ (Itg $\alpha 7 \beta 1$ ) is localized to the basal membrane of satellite cells and binds laminin present in the basal lamina. 
R.S. Krauss et al.

binding factor required for Notch-mediated transcriptional responses (Fortini 2009). When Rbpj was conditionally mutated in adult mouse satellite cells, these cells were depleted as a result of spontaneous activation and terminal differentiation in the absence of self-renewal (Bjornson et al. 2012; Mourikis et al. 2012). Consequently, such animals failed to regenerate skeletal muscles in response to injury. Combined germline knockout of Heyl and HeyL (also called Hesr1 and Hesr3) resulted in a similar, although not identical, phenotype, suggesting they are relevant Notch target genes (Fukada et al. 2011).

Presumably, Notch ligands on myofibers activate Notch receptors on satellite cells to stimulate contact-dependent signals that maintain quiescence in the absence of injury. The identity of the relevant Notch receptors expressed by satellite cells and Notch ligands expressed by myofibers is not known. Notch3 is likely to be involved, as its germline mutation resulted in perturbation of satellite cell proliferation (Kitamoto and Hanaoka 2010), but the phenotype of these mice was distinct from, and mild relative to, that seen in $R b p j$ conditional mutants or Hey1/HeyL double knockouts. Resting satellite cells also express Notch1 and Notch2 (Bjornson et al. 2012; Mourikis et al. 2012), so signaling by multiple Notch receptors may be involved in maintenance of quiescence. Although Notch/ RBP-J signaling is clearly a key regulator of satellite cell quiescence, the transcriptional targets that are responsible for the long-term maintenance of this fascinating cellular state are not yet illuminated. Although Hes/Hey factors are proximal downstream components, they are transcriptional regulators themselves, so must be acting to help control a quiescence program. It is worth noting that Notch signaling is also required for satellite cells to occupy their niche in late development and, in its absence, satellite cells remain in the interstitium between fibers (Bröhl et al. 2012). The relationship between this function for Notch signaling and Notch's role in maintenance of quiescence in adult satellite cells is unexplored and of high interest.

Based on its specific expression pattern and localization, M-cadherin (encoded by Cdh15) seems well suited to play a role in fiber-satellite cell communication. However, the germline Cdh15 mouse mutant displayed little to no phenotype in skeletal muscle development or regeneration (Hollnagel et al. 2002). Satellite cells express additional classical cadherins, which are likely to act redundantly with $\mathrm{M}$-cadherin in satellite cell function. For example, we have observed that satellite cells that lack both $\mathrm{N}$ - and $\mathrm{M}$-cadherin were prone to activation in the absence of injury, suggesting cadherins play a role in maintenance of quiescence (AJ Goel and RS Krauss, in prep.). This topic warrants further attention, as does the general subject of adhesive interactions between myofibers and their associated satellite cells.

\section{CONCLUDING REMARKS}

Most research on the role of cell junctions and cell-cell contact-dependent signaling in skeletal muscle development has been focused on interactions between myoblasts that promoted differentiation and fusion, or formation of neuromuscular junctions (Krauss 2010; Kim et al. 2015; Tintignac et al. 2015). Recent studies have shown that cell-cell contact between various nonmuscle and muscle cell types is important for several steps of myogenesis and provided mechanistic information on these processes. Commitment of progenitor cells to the skeletal muscle lineage, postnatal growth of fibers by recruitment of myoblasts to sites of fusion, and fiber-type patterning are each regulated in this manner. Therefore, cell-cell contact-dependent signaling is important at most, if not all, steps of myogenesis (Table 1).

Many questions remain. The details of the downstream signaling events triggered by Notch receptors, cadherins, ephrins, and other adhesion receptors in most stages of myogenesis are not well understood. Additionally, it is clear that contact between cells in some of these processes is transient. How long such cells must be in direct contact for successful signaling, how contact is broken, and the molecular nature of the cell junctions that support signaling are all interesting questions. Despite tremendous progress in understanding mechanisms of myoblast 
Cell-Cell Contact and Skeletal Myogenesis

Table 1. Roles of cell-cell contact-dependent mechanisms in various steps of myogenesis

\begin{tabular}{|c|c|}
\hline Process in myogenesis & Cell-cell contact-dependent mechanism involved ${ }^{a}$ \\
\hline Lineage commitment & $\begin{array}{l}\text { Delta/Notch signaling between neural crest cells and dermomyotomal muscle } \\
\text { progenitor cells }(+)\end{array}$ \\
\hline Myoblast differentiation & $\begin{array}{l}\text { Delta/Notch signaling }(-) \\
\quad \mathrm{N} \text {-cadherin/Cdon } \rightarrow \text { p38 signaling }(+)\end{array}$ \\
\hline Myoblast fusion & Species-specific adhesion receptors $(+)$ Myomaker $^{\mathrm{b}}(+)$ \\
\hline $\begin{array}{l}\text { Postnatal myofiber growth via } \\
\text { promotion of myoblast } \\
\text { migration to sites of fusion }\end{array}$ & Ephrin-A5/Eph signaling between $\mathrm{NG}^{+}$interstitial cells and myoblasts $(+)$ \\
\hline Fiber-type patterning & $\begin{array}{l}\text { Ephrin-A3/Eph8 signaling between slow fibers and Schwann cells at sites of } \\
\text { innervation }(+)\end{array}$ \\
\hline $\begin{array}{l}\text { Maintenance of the quiescent } \\
\text { satellite cell niche }\end{array}$ & $\begin{array}{l}\text { Delta/Notch signaling between myofibers and satellite cells }(+) \\
\text { Cadherin-based adhesion between myofibers and satellite cells }(+)\end{array}$ \\
\hline
\end{tabular}

fusion, the adhesion receptors required in vertebrate species are not fully identified. The discovery of myomaker was groundbreaking, and studies on whether it is the long elusive fusogen, what its interacting partners are, and how it works are of high interest. Finally, it is somewhat ironic that the stable cell-cell junction present between myofibers and their associated satellite cells resembles well-studied junctions in other tissues, yet is poorly characterized and how it regulates satellite cell biology is largely unknown. Continued study with a variety of model organisms will surely illuminate these questions. Furthermore, the growing emphasis on understanding regenerative myogenesis (which is similar but not identical to developmental myogenesis) and its implications for muscle diseases and aging will bring deserved attention to these fundamental questions.

\section{ACKNOWLEDGMENTS}

Work in R.S.K.'s laboratory on this subject was supported by grants from the National Institutes of Health (NIH) (AR046207 and AR070231).

\section{REFERENCES}

Abmayr SM, Pavlath GK. 2012. Myoblast fusion: Lessons from flies and mice. Development 139: 641-656.
Allen BL, Song JY, Izzi L, Althaus IW, Kang JS, Charron F, Krauss RS, McMahon AP. 2011. Overlapping roles and collective requirement for the co-receptors Gas1, Cdo and Boc in Shh pathway function. Dev Cell 20: 775-787.

Bae GU, Yang YJ, Jiang G, Hong M, Lee HJ, Tessier-Lavigne M, Kang JS, Krauss RS. 2009. Neogenin regulates skeletal myofiber size and focal adhesion kinase and extracellular signal-regulated kinase activities in vivo and in vitro. $\mathrm{Mol}$ Biol Cell 20: 4920-4931.

Biressi S, Molinaro M, Cossu G. 2007. Cellular heterogeneity during vertebrate skeletal muscle development. Dev Biol 308: $281-293$.

Bischoff R. 1990. Interaction between satellite cells and skeletal muscle fibers. Development 109: 943-952.

Bjornson C, Cheung T, Liu L, Tripathi P, Steeper K, Rando T. 2012. Notch signaling is necessary to maintain quiescence in adult muscle stem cells. Stem Cells 30: 232-242.

Borello U, Berarducci B, Murphy P, Bajard L, Buffa V, Piccolo S, Buckingham M, Cossu G. 2006. The Wnt/ $\beta$-catenin pathway regulates Gli-mediated Myf5 expression during somitogenesis. Development 133: 3723-3732.

Borycki AG, Brunk B, Tajbakhsh S, Buckingham M, Chiang C, Emerson CP Jr, 1999. Sonic hedgehog controls epaxial muscle determination through Myf5 activation. Development 126: 4053-4063.

Brack AS, Rando TA. 2012. Tissue-specific stem cells: Lessons from the skeletal muscle satellite cell. Cell Stem Cell 10: $504-514$.

Brand-Saberi B, Christ B. 2000. Evolution and development of distinct cell lineages derived from somites. Curr Top Dev Biol 48: 1-42.

Briata P, Forcales SV, Ponassi M, Corte G, Chen CY, Karin M, Puri PL, Gherzi R. 2005. p38-dependent phosphorylation of the mRNA decay-promoting factor KSRP controls the stability of select myogenic transcripts. Mol Cell 20: 891-903.

Bröhl D, Vasyutina E, Czajkowski MT, Griger J, Rassek C, Rahn HP, Purfürst B, Wende H, Birchmeier C. 2012. Colonization of the satellite cell niche by skeletal muscle 
R.S. Krauss et al.

progenitor cells depends on Notch signals. Dev Cell 23: 469-481.

Chakkalakal JV, Jones KM, Basson MA, Brack AS. 2012. The aged niche disrupts muscle stem cell quiescence. Nature 490: 355-360.

Charlton CA, Mohler WA, Radice GL, Hynes RO, Blau HM. 1997. Fusion competence of myoblasts rendered genetically null for N-cadherin in culture. J Cell Biol 138: 331336.

Cheung TH, Quach NL, Charville GW, Liu L, Park L, Edalati A, Yoo B, Hoang P, Rando TA. 2012. Maintenance of muscle stem-cell quiescence by microRNA-489. Nature 482: 524-528.

Cinnamon Y, Ben-Yair R, Kalcheim C. 2006. Differential effects of N-cadherin-mediated adhesion on the development of myotomal waves. Development 133: 1102 1112.

Cole F, Zhang W, Geyra A, Kang JS, Krauss RS. 2004. Positive regulation of myogenic bHLH factors and skeletal muscle development by the cell surface receptor CDO. Dev Cell 7: 843-854.

Comai G, Tajbakhsh S. 2014. Molecular and cellular regulation of skeletal myogenesis. Curr Top Dev Biol 110: 1 73.

de Angelis L, Zhao J, Andreucci JJ, Olson EN, Cossu G, McDermott JC. 2005. Regulation of vertebrate myotome development by the p38 MAP kinase-MEF2 signaling pathway. Dev Biol 283: 171-179.

Doles JD, Olwin BB. 2015. Muscle stem cells on the edge. Curr Opin Genet Dev 34: 24-28.

Donoviel DB, Freed DD, Vogel H, Potter DG, Hawkins E, Barrish JP, Mathur BN, Turner CA, Geske R, Montgomery CA, et al. 2001. Proteinuria and perinatal lethality in mice lacking NEPH1, a novel protein with homology to NEPHRIN. Mol Cell Biol 21: 4829-4836.

Duan R, Jin P, Luo F, Zhang G, Anderson N, Chen EH. 2012. Group I PAKs function downstream of Rac to promote podosome invasion during myoblast fusion in vivo. J Cell Biol 199: 169-185.

Dumont NA, Wang YX, Rudnicki MA. 2015. Intrinsic and extrinsic mechanisms regulating satellite cell function. Development 142: 1572-1581.

Fischer-Lougheed J, Liu JH, Espinos E, Mordasini D, Bader CR, Belin D, Bernheim L. 2001. Human myoblast fusion requires expression of functional inward rectifier Kir2.1 channels. J Cell Biol 153: 677-686.

Fong AP, Tapscott SJ. 2013. Skeletal muscle programming and re-programming. Curr Opin Genet Dev 23: 568-573.

Fortini ME. 2009. Notch signaling: The core pathway and its posttranslational regulation. Dev Cell 16: 633-647.

Fry CS, Lee JD, Mula J, Kirby TJ, Jackson JR, Liu F, Yang L, Mendias CL, Dupont-Versteegden EE, McCarthy JJ, et al. 2015. Inducible depletion of satellite cells in adult, sedentary mice impairs muscle regenerative capacity without affecting sarcopenia. Nat Med 21: 76-80.

Fukada S, Yamaguchi M, Kokubo H, Ogawa R, Uezumi A, Yoneda T, Matev MM, Motohashi N, Ito T, Zolkiewska A, et al. 2011. Hesr1 and Hesr3 are essential to generate undifferentiated quiescent satellite cells and to maintain satellite cell numbers. Development 138: 4609-4619.
Galletta BJ, Chakravarti M, Banerjee R, Abmayr SM. 2004. SNS: Adhesive properties, localization requirements and ectodomain dependence in S2 cells and embryonic myoblasts. Mech Dev 121: 1455-1468.

Gliki G, Ebnet K, Aurrand-Lions M, Imhof BA, Adams RH. 2004. Spermatid differentiation requires the assembly of a cell polarity complex downstream of junctional adhesion molecule-C. Nature 431: 320-324.

Gopinath S, Webb A, Brunet A, Rando T. 2014. FOXO3 promotes quiescence in adult muscle stem cells during the process of self-renewal. Stem Cell Rep 2: 414-426.

Gruenbaum-Cohen Y, Harel I, Umansky K, Tzahor E, Snapper SB, Shilo BZ, Schejter ED. 2012. The actin regulator N-WASp is required for muscle-cell fusion in mice. Proc Nati Acad Sci 109: 11211-11216.

Gu J-M, Wang DJ, Peterson JM, Shintaku J, Liyanarachchi S, Coppola V, Frakes AE, Kaspar BK, Cornelison DD, Guttridge DC. 2016. An NF-кB-ephrinA5-dependent communication between $\mathrm{NG}^{+}$interstitial cells and myoblasts promotes muscle growth in neonates. Dev Cell 36: $215-224$.

Guasconi V, Puri PL. 2009. Chromatin: The interface between extrinsic cues and the epigenetic regulation of muscle regeneration. Trends Cell Biol 19: 286-294.

Hindi SM, Tajrishi MM, Kumar A. 2013. Signaling mechanisms in mammalian myoblast fusion. Sci Signal 6: re2.

Hollnagel A, Grund C, Franke WW, Arnold HH. 2002. The cell adhesion molecule M-cadherin is not essential for muscle development and regeneration. Mol Cell Biol 22: 4760-4770.

Jeong MH, Ho SM, Vuong TA, Jo SB, Liu G, Aaronson SA, Leem YE, Kang JS. 2014. Cdo suppresses canonical Wnt signalling via interaction with Lrp6 thereby promoting neuronal differentiation. Nat Commun 19: 5455.

Joseph GA, Lu M, Radu M, Lee J, Burden SJ, Chernoff J, Krauss RS. 2016. Group I Paks promote myoblast differentiation in vivo and in vitro. Mol Cell Biol doi:10.1128/ MCB.00222-16.

Kang J-S, Gao M, Feinleib JL, Cotter PD, Guadagno SN, Krauss RS. 1997. CDO: An oncogene-, serum-, and anchorage-regulated member of the Ig/fibronectin type III repeat family. J Cell Biol 138: 203-213.

Kang J-S, Mulieri PJ, Miller C, Sassoon DA, Krauss RS. 1998. $\mathrm{CDO}$, a robo-related cell surface protein that mediates myogenic differentiation. J Cell Biol 143: 403-413.

Kang J-S, Feinleib JL, Knox S, Ketteringham MA, Krauss RS. 2003. Promyogenic members of the Ig and cadherin families associate to positively regulate differentiation. Proc Natl Acad Sci 100: 3989-3994.

Kang J-S, Yi MJ, Zhang W, Feinleib JL, Cole F, Krauss RS, 2004. Netrins and neogenin promote myotube formation. J Cell Biol 167: 493-504.

Kang J-S, Bae GU, Yi MJ, Yang YJ, Oh JE, Takaesu G, Zhou YT, Low BC, Krauss RS. 2008. A Cdo/Bnip-2/Cdc42 signaling pathway regulates $\mathrm{p} 38 \alpha / \beta$ MAPK activity and myogenic differentiation. J Cell Biol 182: 497-507.

Keefe AC, Lawson JA, Flygare SD, Fox ZD, Colasanto MP, Mathew SJ, Yandell M, Kardon G. 2015. Muscle stem cells contribute to myofibres in sedentary adult mice. Nat Commun 6: 7807. 
Kim JH, Jin P, Duan R, Chen EH. 2015. Mechanisms of myoblast fusion during muscle development. Curr Opin Genet Dev 32: 162-170.

Kitamoto T, Hanaoka K. 2010. Notch3 null mutation in mice causes muscle hyperplasia by repetitive muscle regeneration. Stem Cells 28: 2205-2216.

Konig S, Hinard V, Arnaudeau S, Holzer N, Potter G, Bader CR, Bernheim L. 2004. Membrane hyperpolarization triggers myogenin and myocyte enhancer factor-2 expression during human myoblast differentiation. J Biol Chem 279: 28187-28196.

Krauss RS. 2007. Evolutionary conservation in myoblast fusion. Nat Genet 39: 704-705.

Krauss RS. 2010. Regulation of promyogenic signal transduction by cell-cell contact and adhesion. Exp Cell Res 316: $3042-3049$.

Krauss RS, Cole F, Gaio U, Takaesu G, Zhang W, Kang JS. 2005. Close encounters: Regulation of vertebrate skeletal myogenesis by cell-cell contact. J Cell Sci 118: 2355-2362.

Landemaine A, Rescan PY, Gabillard J-C. 2014. Myomaker mediates fusion of fast myocytes in zebrafish embryos. Biochem Biophys Res Commun 451: 480-484.

Laurin M, Fradet N, Blangy A, Hall A, Vuori K, Côté JF. 2008. The atypical Rac activator Dock180 (Dock1) regulates myoblast fusion in vivo. Proc Natl Acad Sci 105: 15446-15451.

Lee HJ, Bae G, Leem YE, Choi HK, Kang TM, Cho H, Kim ST, Kang JS. 2012. Phosphorylation of Stim1 at serine 575 via netrin-2/Cdo-activated ERK1/2 is critical for the promyogenic function of Stim1. Mol Biol Cell 23: 1376-1387.

Leem YE, Jeong HJ, Kim HJ, Koh J, Kang K, Bae GU, Cho H, Kang JS. 2016. Cdo regulates surface expression of Kir2.1 $\mathrm{K}^{+}$channel in myoblast differentiation. PLoS ONE 11: e0158707.

Lisabeth EM, Falivelli G, Pasquale EB. 2013. Eph receptor signaling and ephrins. Cold Spring Harb Perspect Biol 5: a009159.

Lluis F, Ballestar E, Suelves M, Esteller M, Munoz-Canoves P. 2005. E47 phosphorylation by p38 MAPK promotes $\mathrm{MyoD} / \mathrm{E} 47$ association and muscle-specific gene transcription. EMBO J 24: 974-984.

Lu M, Krauss RS. 2010. N-cadherin ligation, but not Sonic hedgehog binding, initiates Cdo-dependent p38 $\alpha / \beta$ MAPK signaling in skeletal myoblasts. Proc Natl Acad Sci 107: 4212-4217.

Marthiens V, Gavard J, Lambert M, Mège RM. 2002. Cadherin-based cell adhesion in neuromuscular development. Biol Cell 94: 315-326.

Martìn-Padura I, Lostaglio S, Schneemann M, Williams L, Romano M, Fruscella P, Panzeri C, Stoppacciaro A, Ruco Li, Villa A, et al. 1998. Junctional adhesion molecule, a novel member of the immunoglobulin superfamily that distributes at intercellular junctions and modulates monocyte transmigration. J Cell Biol 142: 117-127.

McCrea PD, Maher MT, Gottardi CJ. 2015. Nuclear signaling from cadherin adhesion complexes. Curr Top Dev Biol 112: $129-196$.

Millay DP, O'Rourke JR, Sutherland LB, Bezprozvannaya S, Shelton JM, Bassel-Duby R, Olson EN. 2013. Myomaker is a membrane activator of myoblast fusion and muscle formation. Nature 499: 301-305.

Millay DP, Sutherland LB, Bassel-Duby R, Olson EN. 2014. Myomaker is essential for muscle regeneration. Genes Dev 28: 1641-1646.

Millay DP, Gamage DG, Quinn ME, Min YL, Mitani Y, Bassel-Duby R, Olson EN. 2016. Structure-function analysis of myomaker domains required for myoblast fusion. Proc Natl Acad Sci 113: 2116-2121.

Moore CA, Parkin CA, Bidet Y, Ingham PW. 2007. A role for the Myoblast city homologues Dock 1 and Dock 5 and the adaptor proteins Crk and Crk-like in zebrafish myoblast fusion. Development 134: 3145-3153.

Mourikis P, Sambasivan R, Castel D, Rocheteau P, Bizzarro V, Tajbakhsh S. 2012. A critical requirement for Notch signaling in maintenance of the quiescent skeletal muscle stem cell state. Stem Cells 30: 243-252.

Munsterberg AE, Lassar AB. 1995. Combinatorial signals from the neural tube, floor plate and notochord induce myogenic bHLH gene expression in the somite. Development 121: 651-660.

Munsterberg AE, Kitajewski J, Bumcrot DA, McMahon AP, Lassar AB. 1995. Combinatorial signaling by Sonic hedgehog and Wnt family members induces myogenic bHLH gene expression in the somite. Genes Dev 9: 29112922.

Niessen CM, Leckband D, Yap AS. 2011. Tissue organization by cadherin adhesion molecules: Dynamic molecular and cellular mechanisms of morphogenetic regulation. Physiol Rev 91: 691-731.

Ozawa M. 2015. E-cadherin cytoplasmic domain inhibits cell surface localization of endogenous cadherins and fusion of C2C12 myoblasts. Biol Open 4: 1427-1435.

Palacios D, Mozzetta C, Consalvi S, Caretti G, Saccone V, Proserpio V, Marquez VE, Valente S, Mai A, Forcales SV, et al. 2010. TNF/p38 $\alpha /$ polycomb signaling to Pax7 locus in satellite cells links inflammation to the epigenetic control of muscle regeneration. Cell Stem Cell 7: 455-469.

Powell GT, Wright GJ. 2011. Jamb and jamc are essential for vertebrate myocyte fusion. PLoS Biol 9: e1001216.

Prince JEA, Brignall AC, Cutforth T, Shen K, Cloutier JF 2013. Kirrel3 is required for the coalescence of vomeronasal sensory neuron axons into glomeruli and for malemale aggression. Development 140: 2398-2408.

Putaala H, Soininen R, Kilpeläinen P, Wartiovaara J, Tryggvason K. 2001. The murine nephrin gene is specifically expressed in kidney, brain and pancreas: Inactivation of the gene leads to massive proteinuria and neonatal death. Hum Mol Genet 10: 1-8.

Radice GL, Rayburn H, Matsunami H, Knudsen KA, Takeichi M, Hynes RO. 1997. Developmental defects in mouse embryos lacking N-cadherin. Dev Biol 181: 64-78.

Rampalli S, Li L, Mak E, Ge K, Brand M, Tapscott SJ, Dilworth FJ. 2007. p38 MAPK signaling regulates recruitment of Ash2L-containing methyltransferase complexes to specific genes during differentiation. Nat Struct Mol Biol 14: 1150-1156.

Reshef R, Maroto M, Lassar AB. 1998. Regulation of dorsal somitic cell fates: BMPs and Noggin control the timing and pattern of myogenic regulator expression. Genes Dev 12: $290-303$. 


\section{R.S. Krauss et al.}

Rios AC, Serralbo O, Salgado D, Marcelle C. 2011. Neura crest regulates myogenesis through the transient activation of NOTCH. Nature 473: 532-535.

Sakaguchi T, Nishimoto M, Miyagi S, Iwama A, Morita Y, Iwamori $\mathrm{N}$, Nakauchi $\mathrm{H}$, Kiyonari $\mathrm{H}$, Muramatsu $\mathrm{M}$, Okuda A. 2006. Putative "Stemness" gene Jam-B is not required for maintenance of stem cell state in embryonic, neural, or hematopoietic stem cells. Mol Cell Biol 26: 6557-6570.

Sanes JR, Lichtman JW. 1999. Development of the vertebrate neuromuscular junction. Annu Rev Neurosci 22: 389442.

Sartorelli V, Juan AH. 2011. Sculpting chromatin beyond the double helix: Epigenetic control of skeletal myogenesis. Curr Top Dev Biol 96: 57-83.

Schiaffino S, Reggiani C. 2011. Fiber types in mammalian skeletal muscles. Physiol Rev 91: 1447-1531.

Schuster-Gossler K, Cordes R, Gossler A. 2007. Premature myogenic differentiation and depletion of progenitor cells cause severe muscle hypotrophy in Delta1 mutants. Proc Natl Acad Sci 104: 537-542.

Sens KL, Zhang S, Jin P, Duan R, Zhang G, Luo F, Parachini L, Chen EH. 2010. An invasive podosome-like structure promotes fusion pore formation during myoblast fusion. J Cell Biol 191: 1013-1027.

Serra C, Palacios D, Mozzetta C, Forcales SV, Morantte I, Ripani M, Jones DR, Du K, Jhala US, Simone C, et al. 2007. Functional interdependence at the chromatin level between the MKK6/p38 and IGF1/PI3K/AKT pathways during muscle differentiation. Mol Cell 28: 200213.

Shilagardi K, Li S, Luo F, Marikar F, Duan R, Jin P, Kim JH, Murnen K, Chen EH. 2013. Actin-propelled invasive membrane protrusions promote fusogenic protein engagement during cell-cell fusion. Science 340: 359-363.

Sieiro D, Rios AC, Hirst CE, Marcelle C. 2016. Cytoplasmic $\mathrm{NOTCH}$ and membrane-derived $\beta$-catenin link cell fate choice to epithelial-mesenchymal transition during myogenesis. eLife 24: e14847.

Simone C, Forcales SV, Hill DA, Imbalzano AN, Latella L, Puri PL. 2004. p38 pathway targets SWI-SNF chromatinremodeling complex to muscle-specific loci. Nat Genet 36: $738-743$.

Sohn RL, Huang P, Kawahara G, Mitchell M, Guyon J, Kalluri R, Kunkel LM, Gussoni E. 2009. A role for nephrin, a renal protein, in vertebrate skeletal muscle cell fusion. Proc Natl Acad Sci 106: 9274-9279.

Srinivas BP, Woo J, Leong WY, Roy S. 2007. A conserved molecular pathway mediates myoblast fusion in insects and vertebrates. Nat Genet 39: 781-786.

Stark DA, Coffey NJ, Pancoast HR, Arnold LL, Walker JPD, Vallée J, Robitaille R, Garcia ML, Cornelison DDW. 2015. Ephrin-A3 promotes and maintains slow muscle fiber identity during postnatal development and reinnervation. J Cell Biol 211: 1077-1091.

Stern HM, Hauschka SD. 1995. Neural tube and notocord promote in vitro myogenesis in single somite explants. Dev Biol 167: 87-103.

Stern HM, Brown AMC, Hauschka SD. 1995. Myogenesis in paraxial mesoderm: Preferential induction by dorsal neu- ral tube and by cells expressing Wnt-1. Development 121 3675-3686.

Tajbakhsh S, Borello U, Vivarelli E, Kelly R, Papkoff J, Duprez D, Buckingham M, Cossu G. 1998. Differential activation of Myf5 and MyoD by different Wnts in explants of mouse paraxial mesoderm and the later activation of myogenesis in the absence of Myf5. Development 125: $4155-4162$.

Takaesu G, Kang JS, Bae GU, Yi MJ, Lee CM, Reddy EP, Krauss RS. 2006. Activation of $\mathrm{p} 38 \alpha / \beta$ MAPK in myogenesis via binding of the scaffold protein JLP to the cell surface protein Cdo. J Cell Biol 175: 383-388.

Talbot J, Maves L. 2016. Skeletal muscle fiber type: Using insights from muscle developmental biology to dissect targets for susceptibility and resistance to muscle disease. Wiley Interdiscip Rev Dev Biol 5: 518-534.

Tapscott SJ. 2005. The circuitry of a master switch: Myod and the regulation of skeletal muscle gene transcription. Development 132: 2685-2695.

Thuault S, Hayashi S, Lagirand-Cantaloube J, Plutoni C, Comunale F, Delattre O, Relaix F, Gauthier-Rouviere C. 2013. P-cadherin is a direct PAX3-FOXO1A target involved in alveolar rhabdomyosarcoma aggressiveness. Oncogene 32: 1876-1887.

Tintignac LA, Brenner H-R, Rüegg MA. 2015. Mechanisms regulating neuromuscular junction development and function and causes of muscle wasting. Physiol Rev 95: 809-852.

Tran P, Ho SM, Kim BG, Vuong TA, Leem YE, Bae GU, Kang JS. 2012. TGF- $\beta$-activated kinase 1 (TAK1) and apoptosis signal-regulating kinase 1 (ASK1) interact with the promyogenic receptor Cdo to promote myogenic differentiation via activation of p38MAPK pathway. J Biol Chem 287: 11602-11615.

van Amerongen R, Nusse R. 2009. Towards an integrated view of Wnt signaling in development. Development 136: 3205-3214.

Vasyutina E, Lenhard DC, Wende H, Erdmann B, Epstein JA, Birchmeier C. 2007. RBP-J (Rbpsuh) is essential to maintain muscle progenitor cells and to generate satellite cells. Proc Natl Acad Sci 104: 4443-4448.

Vasyutina E, Martarelli B, Brakebusch C, Wende H, Birchmeier C. 2009. The small G-proteins Racl and Cdc42 are essential for myoblast fusion in the mouse. Proc Natl Acad Sci 106: 8935-8940.

Vite A, Radice GL. 2014. N-cadherin/catenin complex as a master regulator of intercalated disc function. Cell Commun Adhes 21: 169-179.

Wu Z, Woodring PJ, Bhakta KS, Tamura K, Wen F, Feramisco JR, Karin M, Wang JY, Puri PL. 2000. p38 and extracellular signal-regulated kinases regulate the myogenic program at multiple steps. Mol Cell Biol 20: 3951-3964.

Yesildag B, Bock T, Herrmanns K, Wollscheid B, Stoffel M. 2015. Kin of IRRE-like protein 2 Is a phosphorylated glycoprotein that regulates basal insulin secretion. J Biol Chem 290: 25891-25906.

Zhang W, Kang JS, Cole F, Yi MJ, Krauss RS. 2006. Cdo functions at multiple points in the Sonic Hedgehog pathway, and Cdo-deficient mice accurately model human holoprosencephaly. Dev Cell 10: 657-665. 


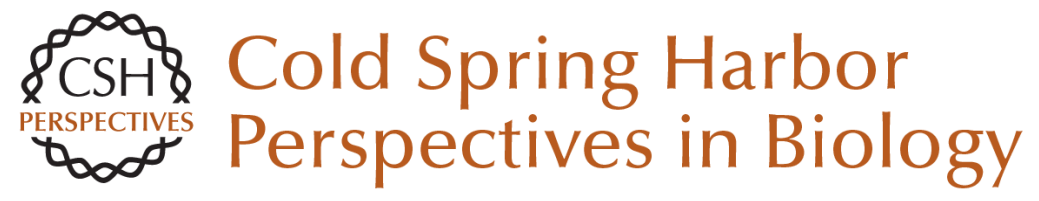

\section{Keep Your Friends Close: Cell-Cell Contact and Skeletal Myogenesis}

Robert S. Krauss, Giselle A. Joseph and Aviva J. Goel

Cold Spring Harb Perspect Biol 2017; doi: 10.1101/cshperspect.a029298 originally published online January 6, 2017

\section{Subject Collection Cell-Cell Junctions}

Vascular Endothelial (VE)-Cadherin, Endothelial Adherens Junctions, and Vascular Disease Maria Grazia Lampugnani, Elisabetta Dejana and Costanza Giampietro

Adherens Junctions and Desmosomes Coordinate Mechanics and Signaling to Orchestrate Tissue Morphogenesis and Function: An Evolutionary Perspective Matthias Rübsam, Joshua A. Broussard, Sara A. Wickström, et al.

Cell-Cell Contact and Receptor Tyrosine Kinase Signaling Christine Chiasson-MacKenzie and Andrea I. McClatchey

Hold Me, but Not Too Tight--Endothelial Cell-Cell Junctions in Angiogenesis Anna Szymborska and Holger Gerhardt

\section{Connexins and Disease} Mario Delmar, Dale W. Laird, Christian C. Naus, et al.

\section{Cell Junctions in Hippo Signaling}

Ruchan Karaman and Georg Halder

Loss of E-Cadherin-Dependent Cell-Cell Adhesion and the Development and Progression of Cancer Heather C. Bruner and Patrick W.B. Derksen
Signaling by Small GTPases at Cell-Cell Junctions: Protein Interactions Building Control and Networks Vania Braga

Making Connections: Guidance Cues and Receptors at Nonneural Cell-Cell Junctions Ian V. Beamish, Lindsay Hinck and Timothy E. Kennedy

The Cadherin Superfamily in Neural Circuit Assembly James $D$. Jontes

Mechanosensing and Mechanotransduction at Cell-Cell Junctions Alpha S. Yap, Kinga Duszyc and Virgile Viasnoff

Beyond Cell-Cell Adhesion: Sensational

Cadherins for Hearing and Balance Avinash Jaiganesh, Yoshie Narui, Raul Araya-Secchi, et al.

Cell-Cell Junctions Organize Structural and Signaling Networks Miguel A. Garcia, W. James Nelson and Natalie Chavez

Cell Biology of Tight Junction Barrier Regulation and Mucosal Disease Aaron Buckley and Jerrold R. Turner

For additional articles in this collection, see http://cshperspectives.cshlp.org/cgi/collection/

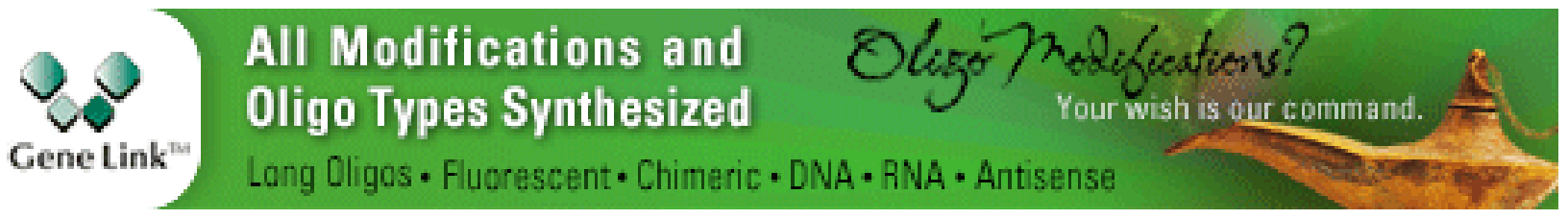


Desmosomes and Intermediate Filaments: Their Consequences for Tissue Mechanics Mechthild Hatzfeld, René Keil and Thomas M. Magin
Integration of Cadherin Adhesion and

Cytoskeleton at Adherens Junctions

René Marc Mège and Noboru Ishiyama

For additional articles in this collection, see http://cshperspectives.cshlp.org/cgi/collection/

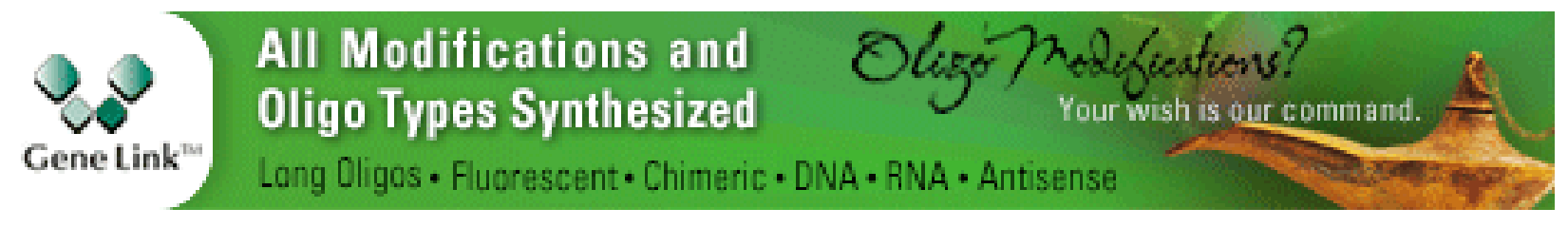

Copyright @ 2017 Cold Spring Harbor Laboratory Press; all rights reserved 